\title{
Intraoperative Predictors of Difficult Laparoscopic Cholecystectomy: AMU Scoring System
}

\author{
Mohammad S Akhtar ${ }^{1}$, Parwez Alam², Yasir Alvi ${ }^{3}$, Isna R Khan ${ }^{4}$, Syed AA Rizvi ${ }^{5}$, Mohammad H Raza ${ }^{6}$
}

\begin{abstract}
Introduction: With laparoscopy being the surgeon's first choice even in difficult cholecystectomy, a need to objectively grade intraoperative difficulty during laparoscopic cholecystectomy (LC) is gaining popularity. The study was done to design a scoring system to predict the difficult outcome during intraoperative LC.

Materials and methods: The study was done at the General Surgery Department in a tertiary level hospital among patients undergoing LC. The procedures that exceeded 70 minutes in duration and/or converted to open were considered the difficult LC. To develop the predictive score, an association of various factors with difficult cholecystectomy was identified by performing multiple logistic regression analysis, and receiver operating characteristic (ROC) curve was plotted to estimate the cutoff value for the scoring system.

Results: We recruited 200 patients in this study, out of which 85 had difficult cholecystectomy procedures. Among all intraoperative predictors, adhesions, gallbladder (GB) condition, Calot's triangle status and abnormality, and the presence of pericholecystic fluid were associated with a difficult LC. Based on the odds ratio, a new scoring system was designed with a score ranging from 0 to 25 . The grading score was created as easy ( $0-5)$ and difficult ( 6 or above) based on the intraoperative factors. At a cutoff score of 6 , this scoring system had a sensitivity and specificity of 87.1 and $88.7 \%$, respectively.

Conclusion: This study demonstrates that an intraoperative scoring system can predict the difficult outcome of LC. This can help in minimizing the complication and conversion to open cholecystectomy, especially relevant for funds-limited settings like India.

Keywords: Cholecystectomy, Conversion to open and Calot's triangle, Laparoscopic, Operative scoring system.

World Journal of Laparoscopic Surgery (2021): 10.5005/jp-journals-10033-1454
\end{abstract}

\section{INTRODUCTION}

Laparoscopic cholecystectomy (LC) has transformed the whole approach to the treatment of symptomatic cholelithiasis. In the beginning, surgeons felt comfortable operating only the simple gallbladders (GB) by LC, but with the increase in expertise and newer armory, it is also becoming surgeon's first choice even in difficult cholecystectomy. However, LC can be difficult in various situations, especially in a surgeon's early career, which makes them a little stressed. ${ }^{1}$ Various problem faced includes difficulty in creating pneumoperitoneum, accessing peritoneal cavity, releasing adhesions, identifying the anatomy, anatomical variations, and extracting the $\mathrm{GB}^{2,3}$ It can be more difficult in males than in females who are also more commonly diagnosed with cholelithiasis requiring surgery. ${ }^{4,5}$

The term difficult cholecystectomy refers to multiple technical intraoperative difficulties that increase the risk of complications and significantly prolong the operative time. ${ }^{6}$ Difficult LC is related to an increased incidence of conversion to open cholecystectomy, probably because of greater difficulty in operation, and therefore, greater is a likelihood of conversion to open technique. ${ }^{7}$ At the same time, the level of difficulty may vary with the skill and experience of the surgeon. ${ }^{7}$ While many preoperative LC assessments are available, there are only a few intraoperative laparoscopic surgeries difficultly predicting the criteria, leaving a gap in studying important factors that can help in preventing complications beforehand. ${ }^{8}$ Thus, this study was done to develop a scoring system to predict the difficult outcome during intraoperative LC.
1,2,4-6 Department of Surgery, Jawaharlal Nehru Medical College and Hospital, Aligarh Muslim University, Aligarh, Uttar Pradesh, India

${ }^{3}$ Department of Community Medicine, Jawaharlal Nehru Medical College and Hospital, Aligarh Muslim University, Aligarh, Uttar Pradesh, India

Corresponding Author: Parwez Alam, Department of Surgery, Jawaharlal Nehru Medical College and Hospital, Aligarh Muslim University, Aligarh, Uttar Pradesh, India, Phone: +91 9045974632, e-mail: parwez786amu@ gmail.com

How to cite this article: Akhtar MS, Alam P, Alvi Y, et al. Intraoperative Predictors of Difficult Laparoscopic Cholecystectomy: AMU Scoring System. World J Lap Surg 2021;14(2):114-118.

Source of support: Nil

Conflict of interest: None

\section{Materials and Methods}

\section{Study Design and Population}

We did a cross-sectional study over a period of 1 year from July 2015 to June 2016. The study population included all patients consulting the surgery outpatient department, Jawaharlal Nehru Medical College, Aligarh, and subsequently diagnosed as a case of cholelithiasis. This hospital is a tertiary referral center and is one of the largest hospitals in the northwest part of the state Uttar Pradesh. A total of 200 patients were diagnosed as cholelithiasis; as per the standard protocol, they were included in the study. Exclusion 
criteria were preoperatively proven GB malignancy, refractory coagulopathy pulmonary disease, end-stage liver disease, and any corticobasal degeneration pathology.

\section{Sampling}

We decided to include all the eligible cases fulfilling the study criteria by undergoing LC under a single surgeon unit for the study. A single surgeon unit criterion was selected to prevent intraobserver bias. Surgeons with experience of more than 50 LCs did all the surgeries in this study. For the selection of cases, consecutive sampling was done. During the study period, a total of 200 patients undergoing LC who met the study criteria were selected for the study.

\section{Definitions}

Difficult cholecystectomy was defined in this study as

- A total duration of more than 70 minutes for LC from the insertion of Veress needle till the extraction of GB

- Requiring more than 20 minutes to dissect the Calot's triangle

- Requiring more than 20 minutes to dissect the GB from the liver bed

- Conversion to open cholecystectomy

\section{Study Procedure}

After the approval by Institutional Ethics and Research Advisory Committee, JN Medical College, Aligarh, enrollment was started. The patients fulfilling the selection criteria were explained about the study, and those who gave informed consent were selected. The selected patients who were fit for the laparoscopic surgery after preanesthetic checkup were planned for the surgery. During the LC, the following things were taken into notice:

- Abdominal wall scar mark

- Creation of the pneumoperitoneum

- GB condition

- Separation of all adhesions

- Liver condition

- Skeletonization, ligation, and division of cystic artery and cystic duct

- Excision of GB from the GB fossa of the liver bed

- Extraction of GB.

Overlapping of these intraoperative difficulties was recorded. The total duration of the surgery from the insertion of the Veress needle into the closure of the port site as well as the time for Calot's triangle dissection was noted by stopwatch.

\section{Data Management and Statistics}

The data were entered and analyzed in Statistical Package for Social Sciences (SPSS) version 20. Statistical significance was tested first by binary logistic regression analysis, and then, multiple logistic regression analysis was calculated to find out adjusted odds ratio. The odds ratios express how many times a preoperative variable is likely to be found in the difficulty group as compared to the easy group. As adjusted odds ratio had a wide range, to avoid the same for the proposed score, adjusted odds ratios were divided by ten and rounded off to the nearest numerical. The proposed scoring system was tested on the original intraoperative data of the study subjects. The individual score of each patient was calculated. The sensitivity and specificity of the proposed scoring system were computed, and receiver operating characteristic (ROC) curve was plotted to estimate the cutoff value for the scoring system.

\section{RESULTS}

We enrolled 200 patients in our study, out of which 85 patients had difficult LC. The majority of the participants were females $(n=148)$, while the mean age of all the participants was $40.95 \pm 11.08$ years. Most of the patients were presented with chronic cholecystitis. The detail of study participants has been given in the previous publication. ${ }^{9}$ Association of various predictors was analyzed by binary logistic regression analysis, and their adjusted odds ratios were measured as shown in Table 1.

The proposed score for predicting difficult cholecystectomy during intraoperative surgery is given in Table 2 . As seen in the ROC curve (Figs 1 and 2), a score of 6 was selected as the best cutoff point compromise between maximum sensitivity and specificity. A cutoff point at 6 has a sensitivity of $87.1 \%$ and a specificity of $88.7 \%$ (Fig. 2). We also performed internal consistency of the proposed scores by using Cronbach's coefficient alpha, which was 0.71 , which is considered adequate for an attitudinal scale. ${ }^{10}$

\section{Discussion}

The present study was done to design a scoring system predicting difficult outcomes during intraoperative LC. This scoring system would help in identifying high-risk patients who may have difficulty during $L C$ and thus in preventing complications beforehand. The present study assessed various operative factors for $L C$ and found GB condition; GB adhesion, intra-abdominal adhesion, presence of pericholecystic fluid, Calot's triangle status, and cystic duct and vessels abnormality were predicting difficult LC. On basis of these variables, we devise a grading system to evaluate difficulty during LC.

Our study was supported by various studies that also found that significant factors like intra-abdominal adhesion, inflamed GB, frozen Calot's triangle, as well as abnormal anatomy of vessels and cystic duct were predicting difficult LC, although not with others who also observed obesity and previous abdominal scar mark as predictors. ${ }^{3,6,11-15}$ Lal et al. suggest that a difficult LC is one which takes more than 90 minutes for completion and tearing the GB, takes more than 20 minutes in dissecting the GB adhesions, or takes more than 20 minutes in dissecting the Calot's triangle. ${ }^{6}$ While the time taken for Calot's triangle dissection varies based on surgical skills and the level of experience, it is usually longer in patients with difficult access, inflammation, and adhesions. ${ }^{6}$ In this study, we considered that difficult LC takes 70 minutes in completion and 20 minutes each in the dissection of GB from the liver bed and Calot's triangle.

There is limited success in formulating an intraoperative scoring system in LC. One developed by Vivek et al. is complex having 22 parameters including four intraoperative LCs, thus not easy to use. ${ }^{13}$ Their scoring system had a maximum score of 44 , and a score of 9 was predicted as difficult LC with sensitivity and specificity of 85 and $97.8 \%$, respectively. Our scoring system has a sensitivity of $87.1 \%$ and a specificity of $88.7 \%$, with an area under the ROC curve as 0.953 . Another scale proposed by Randhawa et al. was validated in Indian settings by Gupta et al., which graded difficult LC from 0 (easy) to 15 (very difficult). ${ }^{15,16}$ Although their scale is easier, but only a few operative features like thickened ( $\geq 4 \mathrm{~mm}$ ) GB wall and impacted stone are given importance. ${ }^{15}$ Sugrue et al. conducted 
Table 1: Predictors of difficult cholecystectomy based on the results of multiple logistic regression analysis

\begin{tabular}{|c|c|c|c|c|c|}
\hline \multirow[b]{2}{*}{ Predictors } & \multicolumn{2}{|c|}{ Univariate } & \multicolumn{2}{|c|}{ Multivariate } & \multirow[b]{2}{*}{ Score weight } \\
\hline & OR & $p$-value & $A O R$ & $p$-value & \\
\hline \multicolumn{6}{|l|}{ Abdominal wall scar } \\
\hline No scar & Ref & & & & NA \\
\hline Scar present & 0.94 & 0.69 & & & NA \\
\hline \multicolumn{6}{|l|}{ Pneumoperitoneum access } \\
\hline Easy access & Ref & & & & NA \\
\hline Difficult access by repeated attempt & 0.90 & 0.79 & & & NA \\
\hline Access requiring open technique & 1.76 & 0.23 & & & NA \\
\hline \multicolumn{6}{|l|}{ Abdominal adhesions } \\
\hline No adhesions & Ref & & Ref & & 0 \\
\hline Easily separable mild adhesions & 0.51 & 0.54 & 0.000 & 0.99 & 0 \\
\hline Severe adhesions requiring energy & 12.10 & $<0.01$ & 10.87 & 0.03 & 1 \\
\hline Intra-abdominal adhesions & 8.40 & $<0.01$ & 39.10 & $<0.01$ & 4 \\
\hline Intra-abdominal and GB adhesions & 14.03 & $<0.01$ & 225.74 & $<0.01$ & 5 \\
\hline Buried GB & High & $<0.01$ & High & $<0.01$ & 5 \\
\hline \multicolumn{6}{|l|}{ GB condition } \\
\hline Normal & Ref & & Ref & & 0 \\
\hline Distended & 5.63 & $<0.01$ & 10.70 & 0.04 & 1 \\
\hline Edematous and inflamed & 5.0 & $<0.01$ & 6.77 & 0.03 & 1 \\
\hline Contracted and inflamed & 8.36 & $<0.01$ & 10.51 & 0.03 & 2 \\
\hline Congested and inflamed & 14.30 & $<0.01$ & 24.49 & 0.04 & 2 \\
\hline Contracted and congested & 21.67 & $<0.01$ & 34.46 & $<0.01$ & 3 \\
\hline Empyema & High & $<0.01$ & High & $<0.01$ & 5 \\
\hline \multicolumn{6}{|l|}{ Intraoperative pericholecystic fluid } \\
\hline Absent & Ref & & Ref & & 0 \\
\hline Present & 6.69 & 0.02 & 170.46 & $<0.01$ & 5 \\
\hline \multicolumn{6}{|l|}{ Calot's triangle status } \\
\hline Normal/clear & Ref & & Ref & & 0 \\
\hline Partial obscure & 3.33 & 0.02 & 2.00 & 0.57 & 0 \\
\hline Cystic duct abnormality & 4.44 & $<0.01$ & 17.98 & $<0.01$ & 2 \\
\hline Vessel abnormality & 35.56 & $<0.01$ & 524.38 & $<0.01$ & 5 \\
\hline $\begin{array}{l}\text { Partially obscure with cystic duct/vessel } \\
\text { abnormality }\end{array}$ & 17.78 & $<0.01$ & 229.83 & $<0.01$ & 5 \\
\hline Fully frozen & 53.33 & $<0.01$ & 222.88 & $<0.01$ & 5 \\
\hline \multicolumn{6}{|l|}{ Hartman pouch status } \\
\hline Normal/no stone & Ref & & Ref & & 0 \\
\hline Impacted stone & High & $<0.01$ & High & $<0.01$ & 5 \\
\hline \multicolumn{6}{|l|}{ Intraoperative liver status } \\
\hline Normal & Ref & & & & NA \\
\hline Fatty & 0.79 & 0.69 & & & NA \\
\hline Visceroptosis & 1.65 & 0.37 & & & NA \\
\hline \multicolumn{6}{|l|}{ Need for port enlargement/conversion } \\
\hline No & Ref & & Ref & & \\
\hline Yes & 2.94 & 0.01 & 2.49 & 0.39 & NA \\
\hline
\end{tabular}

AOR, adjusted odds ratio; $\mathrm{OR}$, odds ratio

a meta-analysis of all on intraoperative LC scoring system taking GB appearance and distension, access, complications, cystic duct, and artery identification into account and proposed a new scoring system..$^{17}$ This had a score ranging from 0 to 10 , with a score of 2 or more predicted as moderate to severe difficult LC. ${ }^{17}$
We observed predicting a difficult LC is possible with good accuracy by our scoring system. In spite of this, our predicting score has some limitations. Due to nonrandom sampling, small sample size, and nonvalidated scoring system, we could not comment on this generability. It is also observed that defining the level 
Table 2: Proposed AMU scoring system of predicting difficult LC

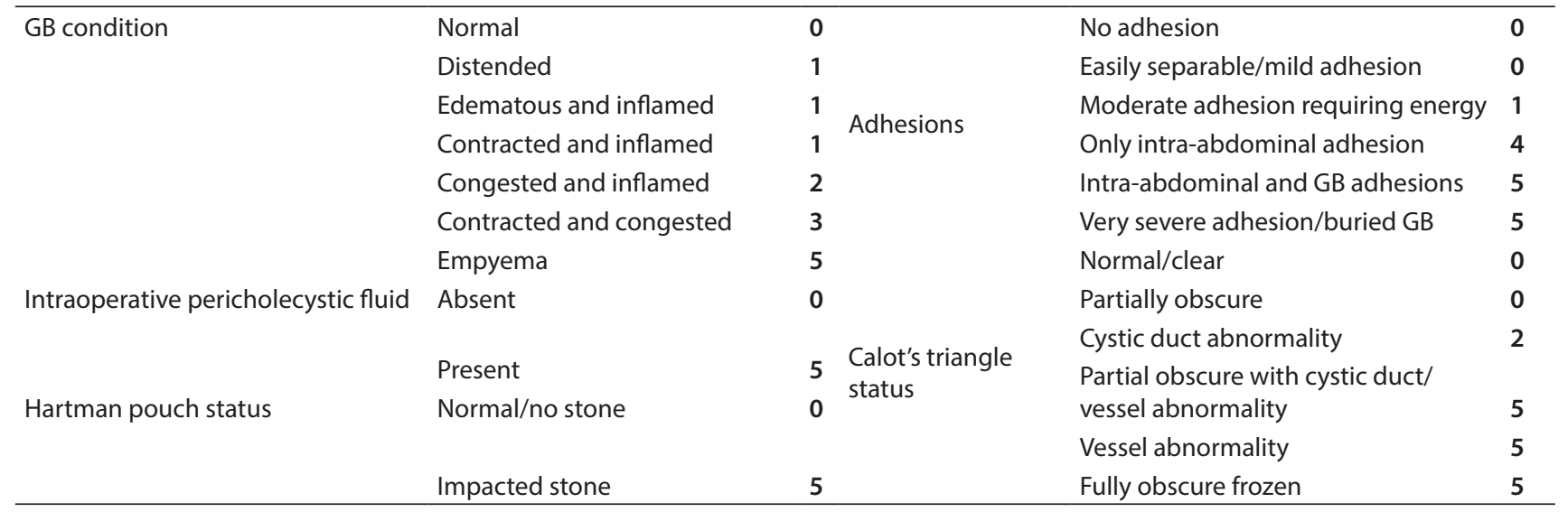

AMU: Aligarh Muslim University

Score 0-5: Easy

Score 6 and above: Difficult

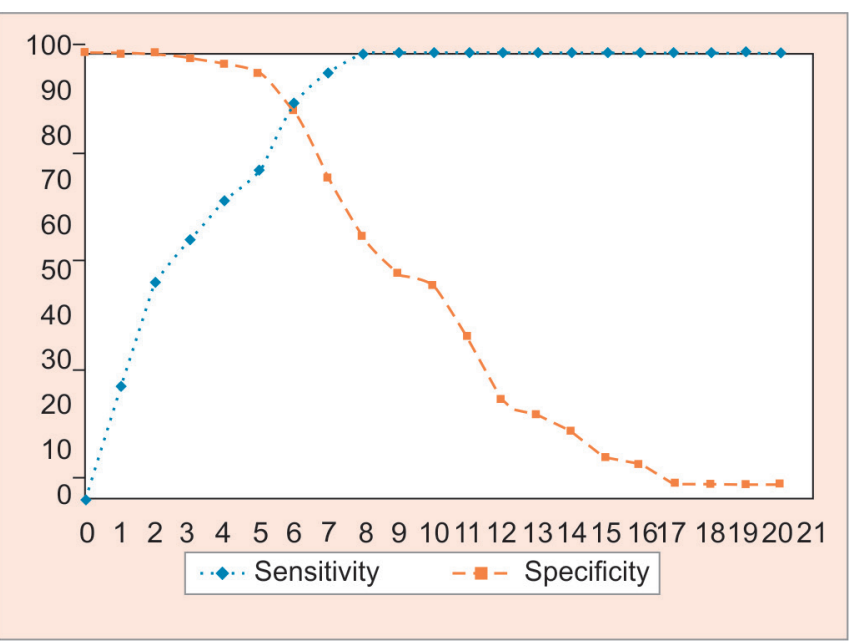

Fig. 1: ROC curve of the proposed score

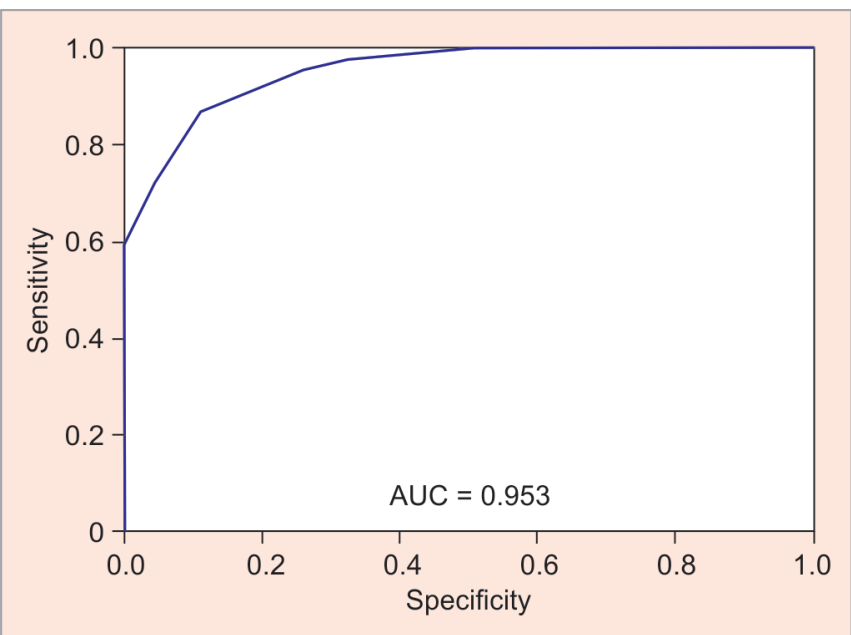

Fig. 2: Specificity and sensitivity curve for calculating the cutoff score

of adhesion, intra-abdominal bleeding, as well as vascularity is nonuniform, and objectifying them may pose difficulties.

\section{Conclusion}

From this study, we concluded a scoring system based on an intraoperative procedure that can identify difficult procedures so as to save time and any untoward complications. Features like intraperitoneal adhesions, structural anomalies or distortions distended or contracted GB, and the frozen Calot's triangle are signs that are associated with difficulties during the surgery. These classification systems would be of great help in improving the outcomes of LC.

\section{References}

1. Daradkeh SS, Suwan Z, Abukhalaf M. Preoperative ultrasonography and prediction of technical difficulties during laparoscopic cholecystectomy. World J Surg 1994;22(1):75-77. DOI: 10.1007/ s002689900352.

2. Augustine A, Rao R, Vivek MAM. A comprehensive predictive scoring method for difficult laparoscopic cholecystectomy. J Minim Access Surg 2014;10(2):62-67. DOI: 10.4103/0972-9941.129947.

3. Nachnani J, Supe A. Pre-operative prediction of difficult laparoscopic cholecystectomy using clinical and ultrasonographic parameters. Ind J Gastro 2005;24:16-18. PMID: 15778520

4. Botaitis S, Polychronidis M, Pitiakoudis M, et al. Does gender affect laparoscopic cholecysytectomy. Surg Laprosc Endosc Percutan Tech 2008;18(2):157-161. DOI: 10.1097/SLE.0b013e318165c899.

5. Yol S, Kartal A, Vatansev C, et al. Sex as a factor in conversion from laparoscopic cholecystectomy to open surgery. JSLS 2006;10(3): 359-363. PMID: 17212896

6. Lal P, Agarwal PN, Malik VK, et al. A difficult laparoscopic cholecystectomy that requires conversion to open procedure can be predicted by preoperative ultrasonography. J Soc Laparoendosc Surg 2002;6(1):59-63. PMID: 12002299

7. Husain A, Pathak S, Firdaus H. Assessment of operative predictors for difficulty in laproscopic cholecystectomy. Int J Contemp Med Res 2016;343:2393-2915. www.ijcmr.com

8. Lipman JM, Claridge JA, Haridas M, et al. Preoperative findings predict conversion from laparoscopic to open cholecystectomy. Surgery 2007;142(4):556-565. DOI: 10.1016/j.surg.2007.07.010.

9. Akhtar MS, Alam P, Alvi Y, et al. A study of factors determining difficult surgery among patients undergoing laparoscopic cholecystectomy. Int Surg J 2019;6(9):3322-3327. DOI: 10.18203/2349-2902.isj20194073.

10. Nunnally JC, Bernstein IH. Psychometric theory. 3rd ed. New York: McGraw-Hill; 1994. 
11. Bat $\mathrm{O}$. The analysis of 146 patients with difficult laparoscopic cholecystectomy. Int J Clin Exp Med 2015;8(9):16127-16131. PMID: 26629124

12. Sahu SK, Agrawal A, Sachan PK. Intraoperative difficulties in laparoscopic cholecystectomy. Jurnalul Chir 2013;9(2):149-155. DOI: 10.7438/1584-9341-9-2-5.

13. Vivek MAKM, Augustine AJ, Rao R. A comprehensive predictive scoring method for difficult laparoscopic cholecystectomy. J Minim Access Surg 2014;10(2):62-67. DOI: 10.4103/0972-9941.129947.

14. Malik A, Laghari AA, Talpur KAH, et al. Laparoscopic cholecystectomy in empyema of gall bladder: an experience at Liaquat University
Hospital, Jamshoro, Pakistan. J Minim Access Surg 2007;3(2):52-56. DOI: 10.4103/0972-9941.33273.

15. Randhawa JS, Pujahari AK. Preoperative prediction of difficult lap chole: a scoring method. Indian J Surg 2009;71(4):198-201. DOI: 10.1007/s12262-009-0055-y.

16. Gupta N, Ranjan G, Arora MP, et al. Validation of a scoring system to predict difficult laparoscopic cholecystectomy. Int J Surg 2013;11(9):1002-1006. DOI: 10.1016/j.ijsu.2013.05.037.

17. Sugrue M, Sahebally SM, Ansaloni L, et al. Grading operative findings at laparoscopic cholecystectomy - a new scoring system. World J Emerg Surg 2015;10(1):14. DOI: 10.1186/s13017-015-0005-x. 